\title{
Análise da relação entre o crescimento populacional e 0 desmatamento no estado do Amapá, Brasil
}

O estado do Amapá, apesar do histórico de baixo desmatamento, apresenta condições propícias ao ciclo de fronteira que ocorre em outras regiões amazônicas, com o agravante de um vertiginoso crescimento populacional, o qual é apontado como fator de indução direto e indireto do desmatamento. Nesse sentido, esta pesquisa teve como objetivo analisar o grau de influência desse fator de indução e suas consequências no âmbito das mudanças de uso do solo no Amapá. Para isso, primeiramente foi analisado o crescimento populacional no estado e em cada um dos seus 16 municípios, por meio de consultas ao Censo Demográfico dos anos de 1980, 1991, 2000 e 2010. Visando identificar a influência do crescimento populacional no desmatamento, foi realizada a análise de Correlação de Pearson (r). A partir disso foi estimada a taxa de desmatamento até o ano de 2030, utilizando regressão linear. A população do Estado cresceu em apenas 36 anos cerca de $325 \%$, propulsionada pela criação das Áreas de Livre Comércio e a elevação da categoria de Território para Estado em 1988. De maneira similar, entre 2000 e 2014 , o desmatamento aumentou $82 \%$. Constatou-se uma forte correlação positiva entre os fatores analisados $(r=0,95)$, comprovando que o crescimento populacional teve influência direta no desmatamento no Estado do Amapá. Considerando o crescente aumento populacional, estimou-se que o Amapá tende a desmatar mais 134.644ha até o ano de 2030. A forte relação constatada no estudo se dá devido ao aumento da demanda interna por alimentos e produtos florestais para atender as necessidades da população em crescimento, assim como as oportunidades do mercado externo, uma vez que o Amapá foi inserido rota de exportação de commodities.

\section{Analysis of the relationship between population growth and deforestation in the state of Amapá, Brazil}

\begin{abstract}
The state of Amapá, despite the history of low deforestation, presents conditions conducive to the border cycle that occurs in other Amazonian regions, with the aggravation of a dizzying population growth, which is pointed as a direct and indirect induction factor of deforestation. In this sense, this research aimed to analyze the degree of influence of this induction factor and its consequences in the context of land use changes in Amapá. To this end, the population growth in the state and in each of its 16 municipalities was first analyzed through consultations to the Demographic Census of the years 1980, 1991, 2000 and 2010. In order to identify the influence of population growth on deforestation, a Pearson's correlation analysis ( $r$ ). From this it was estimated the deforestation rate until the year 2030 , using linear regression. The state's population grew in just 36 years by about $325 \%$, driven by the creation of Free Trade Areas and the elevation of the Territory to State category in 1988. Similarly, between 2000 and 2014, deforestation increased by $82 \%$. There was a strong positive correlation between the factors analyzed $(r=0.95)$, proving that population growth had a direct influence on deforestation in the state of Amapá. Considering the increasing population increase, it has been estimated that Amapá tends to deforest another 134,644 ha by the year 2030. The strong relationship found in the study is due to the increased domestic demand for food and forest products to meet the needs of the population. growth, as well as foreign market opportunities, since Amapá was inserted commodity export route.
\end{abstract}

Keywords: Deforestation Border; Environmental services; Amazon rainforest.

Topic: Planejamento, Gestão e Políticas Públicas Ambientais

Reviewed anonymously in the process of blind peer.

Felipe Ramon Less

Universidade Federal do Pará, Brasil

http://lattes.cnpq.br/2033987543798217

engsmsfelipeless@gmail.com

Diani Fernanda da Silva Less (iD)

Universidade Federal do Oeste do Pará, Brasil

http://lattes.cnpq.br/2305500880087819

http://orcid.org/0000-0002-1197-3583

diani.engambiental@gmail.com

Claudio Fabian Szlafsztein (iD

Universidade Federal do Pará, Brasil

http://lattes.cnpq.br/1348005678649555

http://orcid.org/0000-0002-2855-2056

ioselesz@gmail.com
Received: 24/08/2018

Approved: 29/08/2018
Referencing this:

LESS, F. R.; LESS, D. F. S.; SZLAFSZTEIN, C. F.. Análise da relação entre o crescimento populacional e o desmatamento no estado do Amapá, Brasil. Revista Ibero Americana de Ciências Ambientais, v.9, n.6, p.344-356, 2018. DOI: http://doi.org/10.6008/CBPC2179$\underline{6858.2018 .006 .0032}$

DOI: 10.6008/CBPC2179-6858.2018.006.0032 


\section{INTRODUÇÃO}

A Floresta Amazônica consiste na maior extensão de área com floresta tropical do mundo e vêm sofrendo significativas mudanças nos padrões de uso e cobertura do solo. No Brasil, aproximadamente $18 \%$ da floresta nativa já foi desmatada devido a um processo de ocupação promovido por políticas governamentais com base em modelos desenvolvimentistas e de integração, as quais foram acompanhadas por pressões econômicas nacionais e internacionais (INPE, 2016a; BUTLER, 2016).

O desmatamento nestes ecossistemas representa uma grande fonte de emissão de dióxido de carbono $\left(\mathrm{CO}_{2}\right)$ para a atmosfera, cerca de $12 \%$ das emissões totais de carbono advém das alterações no uso do solo, sendo o desmatamento tropical responsável pela maior parte deste total, devido ao uso do fogo como principal meio de conversão das florestas em pastagens ou áreas agrícolas (QUÉRÉ et al., 2009).

A compreensão dos fatores que causam mudanças nos ecossistemas e em seus serviços ambientais é essencial para a tomada de decisões que minimizem os impactos negativos ou que potencializem os impactos positivos. Fator de indução é qualquer fator natural ou induzido pelo homem que direta ou indiretamente cause uma mudança em um ecossistema. Um fator de indução direto modifica um processo ecossistêmico e pode ser identificado e medido com diferentes graus de precisão. Já um fator de indução indireto opera de forma difusa, influenciando um ou mais fatores de indução diretos, podendo ser mensurado pelos efeitos sobre os condutores diretos (AEM, 2003).

Tanto a ação humana a nível local, que impacta diretamente a floresta, quanto os processos sociais fundamentais, como a dinâmica populacional, as políticas econômicas, agrícolas e de reforma agrária que dão suporte a estas ações humanas, influenciam no processo de mudança de uso do solo. Portanto, o estudo dos fatores de indução como a crescimento populacional, expansão agropecuária, situação fundiária, fatores edafoclimáticos, entre outros que tradicionalmente vêm sendo apontados como causadores do desmatamento na região amazônica, é fundamental para se conhecer mais profundamente o problema (GEIST et al., 2002; COUTINHO et al., 2013).

Diante da inexistência de estudos e pesquisas sobre os fatores de indução ao desmatamento englobando todo o território do Estado do Amapá, em específico com relação ao vertiginoso e recente crescimento populacional ocorrido, o objetivo do trabalho é analisar o grau de influência desse fator de indução e suas consequências no âmbito das mudanças de uso do solo no Amapá.

\section{METODOLOGIA}

\section{Caracterização da área de estudo}

Localizado na região Norte do Brasil e com uma superfície de $142.828 \mathrm{~km}^{2}$, o Estado do Amapá, ilustrado na figura 1, constitui-se no menor dos 9 estados que atualmente compõe a Amazônia Legal, região definida pela Lei no 1.806/1953 com o objetivo de promover o desenvolvimento social e econômico dos estados da região amazônica. O Estado do Amapá possui uma população estimada em 766.679 habitantes distribuída em 16 municípios, fortemente concentrada na área urbana (90\%) sendo que cerca de 75\% 
residem na capital Macapá e na cidade vizinha de Santana, a densidade demográfica é baixa, apresentando 5,37 habitantes por $\mathrm{km}^{2}$, sendo uma das menores densidades demográfica do país (IBGE, 2016a; VIANA et al., 2014).

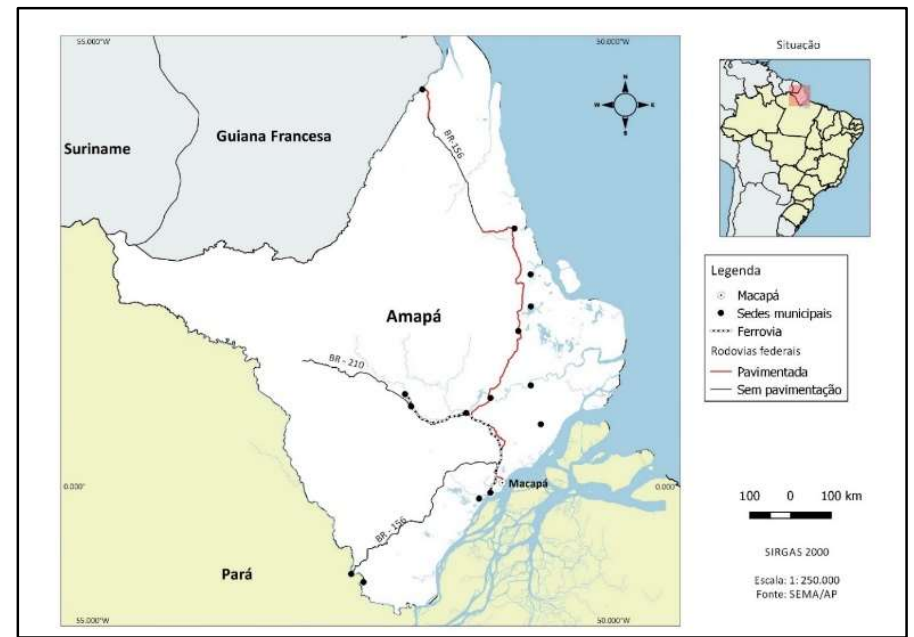

Figura 1: Localização do estado do Amapá e a sede municipal de seus 16 municípios.

Devido ao isolamento territorial, imposto por condições naturais e pela falta de comunicações com os demais estados da federação, o Amapá é a unidade federal que mais sofreu influência do estado brasileiro por meio de uma estratégia nacional de ocupação de áreas de fronteiras pouco povoadas e promoção da exploração de recursos minerais (AMAPÁ, 2014).

Além da instalação do empreendimento minerário Indústria e Comércio de Minérios (ICOMI) no município de Serra do Navio (as obras de infraestrutura do empreendimento se iniciaram em 1954), a instalação do Projeto do Jarí em 1967, época caracterizada pelos grandes empreendimentos na Região Amazônica, são apontados como fatores que contribuíram para o desenvolvimento do Amapá. Bem como, a transformação de Território para Estado pela Constituição de 1988 e a instalação da Área de Livre Comércio nos municípios de Macapá e Santana (AMAPÁ, 2014).

\section{Análise do crescimento demográfico e sua relação com o desmatamento}

Os dados referentes ao crescimento populacional no estado do Amapá, região Norte e do Brasil foram obtidos por meio de consultas ao Censo Demográfico dos anos de 1980, 1991, 2000 e 2010 realizados pelo Instituto Brasileiro de Geografia e Estatística (IBGE, 2016b). Para verificar o perfil do crescimento ocorrido no Estado, foi calculada a Taxa de Crescimento Acumulado para cada ano em relação ao primeiro período.

Para fins de comparação a nível regional e nacional, encontrou-se a Taxa de Crescimento Geométrico da população, proposta pela segunda equação ${ }^{1}$, gerada no software Excel. Tem-se Tx Acumulado $=$ $\left(\frac{P(t+n)}{P(t)}-1\right) \quad$ x 100; e Tx Geométrica $=\sqrt[n]{\frac{p(t+n)}{p(t)}}-1 \quad \mathrm{x} 100$, onde: $\mathrm{n}=0$ número de anos no período; $P(t)=$ população inicial; e $P(t+n)=$ população final.

${ }^{1}$ A taxa geométrica de crescimento foi calculada apenas para o período de 2000 a 2010 , para os períodos anteriores foram utilizados dados do IBGE (2016b). 
Por meio de consulta a dados secundários publicados em documentos oficiais do Governo do Estado do Amapá (AMAPÁ, 2010, 2014) e demais referências bibliográficas identificou-se os fatores responsáveis pelo crescimento populacional e a sua possível relação com as taxas de desmatamento. Para a análise individualizada de cada município amapaense (Tartarugalzinho, Pedra Branca do Amapari, Ferreira Gomes, Cutias, Pracuúba, Porto Grande, Oiapoque, Vitória do Jari, Itaúbal, Macapá, Calçoene, Laranjal do Jari, Amapá, Mazagão, Santana e Serra do Navio) foi considerado o número de habitantes para o período de 2000 a 2014 com base nos dados do IBGE (2016c), a partir dos quais foi encontrado o incremento e o percentual de crescimento populacional. Utilizou-se no trabalho a taxa de desmatamento no Amapá obtida pelo projeto PRODES para o período de 2000 a 2014, disponibilizada pelo INPE (2016b).

Posteriormente, para obter a influência do crescimento demográfico no desmatamento para o período citado acima, foram comparados e correlacionados o crescimento da área desmatada e da população, utilizando a correlação de Pearson ( $r$. No entanto, como o crescimento demográfico é considerado um fator de indução indireto do desmatamento, buscou-se identificar a correlação deste fator com a extração vegetal e agropecuária, a qual é apontada como o principal fator de indução direto do desmatamento na Amazônia.

Foram utilizados dados da Pesquisa de Extração Vegetal e Silvicutura (IBGE, 2016d), de Produção Pecuária Municipal (IBGE, 2016e) e Produção Agrícola Municipal (IBGE, 2016f) do período correspondente de 2000 a 2014 para calcular a correlação entre Pecuária e Produção Agrícola com área desmatada e com a população, visando identificar qual fator tem maior correlação com o desmatamento.

Com base na etapa anterior, visando obter a linha de tendência para o desmatamento até o ano de 2030 por meio de uma regressão linear dos dados da projeção da população amapaense até o ano de 2030 fornecida pelo IBGE (2016d) foi criado um gráfico de dispersão e gerado a equação da reta do crescimento populacional e o coeficiente de determinação $\left(R^{2}\right)$. Foi então utilizada a equação da reta do crescimento populacional para construir a linha de tendência do desmatamento até o ano de 2030 no estado do Amapá.

\section{RESULTADOS E DISCUSSÃO}

O caráter geográfico isolado do Amapá do restante do Brasil aliado à uma população pequena e concentrada, contribuiu para o elevado grau de preservação da cobertura vegetal nativa. Em meados da década de 1990, ainda nos primeiros estudos realizados por meio de técnicas de sensoriamento remoto que visavam o Zoneamento Ecológico Econômico do Amapá se identificou que a área desmatada representava pouco mais de $1 \%$ da sua área total (RABELO, 2008).

No entanto, nas duas últimas décadas esse cenário vem se alterando em decorrência de vários fatores, sendo um deles a alta taxa de natalidade e de migração no Estado que motivaram a partir de 1980 uma taxa de crescimento acelerada da população residente no Estado, principalmente no intervalo entre 1991-2000 (figura 2). 


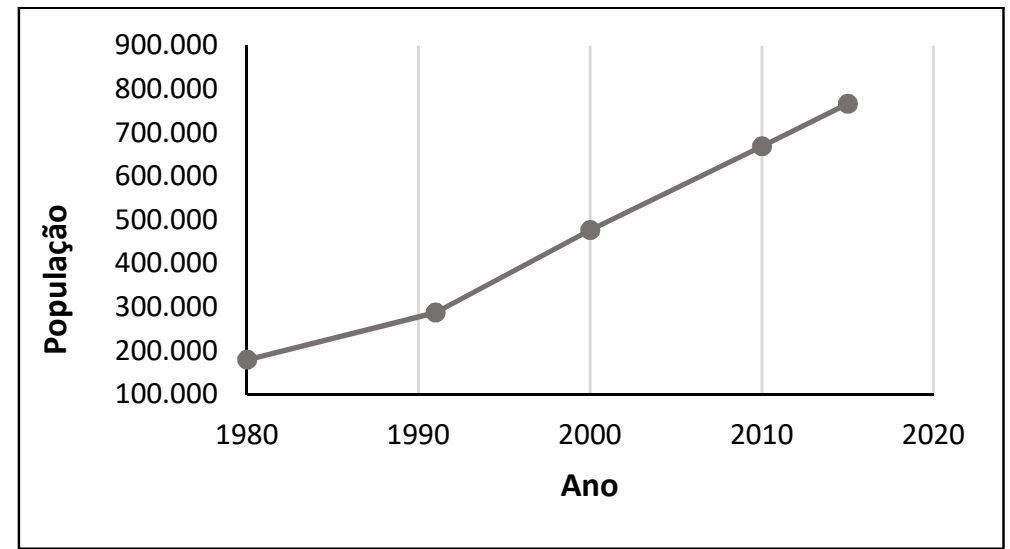

Figura 2: População Residente no Amapá, segundo os Censos de 1980, 1991, 2000 e 2010 do IBGE (b), 2016.

Na figura 2 é possível observar o vertiginoso crescimento ocorrido no Estado nos últimos 30 anos, passando de pouco mais de 180.000 habitantes em 1980 para cerca de 766.679 em 2016, portanto a população do Estado cresceu em apenas 36 anos cerca de $325 \%$. Na tabela 1 é apresentando o crescimento relativo da população verificado nos Censos do IBGE.

Tabela 1: Crescimento Populacional amapaense e taxa de crescimento relativo e líquido no período de 1980 a 2015.

\begin{tabular}{|c|c|c|c|c|c|}
\hline Ano & $\mathbf{1 9 8 0}$ & $\mathbf{1 9 9 1}$ & $\mathbf{2 0 0 0}$ & $\mathbf{2 0 1 0}$ & $\mathbf{2 0 1 5}$ \\
\hline População residente & 180.078 & 288.690 & 477.032 & 669.526 & 766.679 \\
\hline Taxa de crescimento relativo (\%) & & 60,31 & 65,24 & 40,35 & 14,51 \\
\hline Crescimento Líquido & & 108.612 & 188.342 & 192.494 & 97.153 \\
\hline
\end{tabular}

Verifica-se que em termos porcentuais, que o maior crescimento ocorreu no período de 1990 a 2000 $(65,24 \%)$. No entanto, em termos líquidos o crescimento mais representativo se deu no período de 2000 a 2010, quando a população estadual residente cresceu 192.494 habitantes, frente a 188.342 habitantes no período de 1990 a 2000. Diante destas informações, constata-se quem o Estado do Amapá registra as maiores médias anuais de crescimento populacional quando comparado à região Norte e ao restante do país, apesar de demonstrar tendência de queda (tabela 2).

Tabela 2: Taxa média geométrica do estado do Amapá, Região Norte e Brasil.

\begin{tabular}{|c|c|c|c|c|c|c|}
\hline $\begin{array}{c}\text { Grandes Regiões e } \\
\text { Unidades da } \\
\text { Federação }\end{array}$ & \multicolumn{6}{|c|}{ Taxa geométrica média de crescimento da população residente } \\
\cline { 2 - 7 } & $\mathbf{1 9 5 0 / 1 9 6 0}$ & $\mathbf{1 9 6 0 / 1 9 7 0}$ & $\mathbf{1 9 7 0 / 1 9 8 0}$ & $\mathbf{1 9 8 0 / 1 9 9 1}$ & $\mathbf{1 9 9 1 / 2 0 0 0}$ & $\mathbf{2 0 0 0 / 2 0 1 0}$ \\
\hline Brasil & 2,99 & 2,89 & 2,48 & 1,93 & 1,64 & 1,45 \\
\hline Norte & 3,34 & 3,47 & 5,02 & 3,85 & 2,86 & 2,09 \\
\hline Amapá & 6,14 & 5,37 & 4,36 & 4,67 & 5,77 & 3,45 \\
\hline
\end{tabular}

Fonte: IBGE (2016b).

Para explicar este crescimento populacional acentuado, consideram-se dois fatores relevantes que ocorreram a criação das Áreas de Livre Comércio e a elevação da categoria de Território para Estado com a promulgação da Constituição Federal de 1988. Este segundo fator, criou muitas oportunidades de emprego no setor público que representa atualmente $46,2 \%$ do PIB estadual, o que também explica a alta concentração da população (aproximadamente 75\%) na capital (AMAPÁ, 2014b) e criação das Áreas de Livre Comércio.

A grande concentração urbana por um lado é benéfica, por se tratar da ocupação em áreas já urbanizadas evitando o desmatamento nas áreas de floresta, uma vez que essa distribuição espacial 
desequilibrada faz com que o Amapá apresente grandes vazios demográficos, visto que sua densidade populacional relativa ainda é baixa (IBGE, 2016a).

Ainda que a maior parte do crescimento populacional no Estado do Amapá tenha ocorrido na capital Macapá e na vizinha Santana (localiza-se a menos de $20 \mathrm{~km}$ de distância), as cidades do interior também acompanharam este aumento vertiginoso. Entre 2000 e 2014, todos os municípios apresentaram acentuado crescimento, sendo que o incremento populacional médio dos municípios foi de 96\% (tabela 3).

Tabela 3: População dos Municípios que compõe o estado do Amapá e o Incremento Populacional com base nos dados do IBGE (2016c).

\begin{tabular}{|c|c|c|c|c|}
\hline \multirow{2}{*}{ Município } & \multicolumn{2}{|c|}{ No de habitantes } & \multicolumn{2}{c|}{ Crescimento da População (\%) } \\
\cline { 2 - 5 } & $\mathbf{2 0 0 0}$ & $\mathbf{2 0 1 4}$ & Incremento Populacional & $226 \%$ \\
\hline Tartarugalzinho & 4.524 & 14.754 & 10.230 & $225 \%$ \\
\hline Pedra B. do Amapari & 4.130 & 13.411 & 9.281 & $137 \%$ \\
\hline Ferreira Gomes & 2.828 & 6.714 & 3.886 & $132 \%$ \\
\hline Cutias & 2.281 & 5.291 & 3.010 & $128 \%$ \\
\hline Pracuúba & 1.929 & 4.404 & 2.475 & $119 \%$ \\
\hline Porto Grande & 8.760 & 19.191 & 10.431 & $98 \%$ \\
\hline Oiapoque & 11.962 & 23.628 & 11.666 & $77 \%$ \\
\hline Vitória do Jari & 7.952 & 14.045 & 6.093 & $74 \%$ \\
\hline Itaúbal & 2.781 & 4.836 & 2.055 & $67 \%$ \\
\hline Macapá & 267.140 & 446.757 & 179.617 & $54 \%$ \\
\hline Calçoene & 6.119 & 9.979 & 3.860 & $37 \%$ \\
\hline Laranjal do Jari & 28.996 & 44.777 & 15.781 & $42 \%$ \\
\hline Amapá & 6.252 & 8.553 & 2.301 & $29 \%$ \\
\hline Mazagão & 13.504 & 19.157 & 5.653 & $29 \%$ \\
\hline Santana & 85.873 & 110.565 & 24.692 & $\mathbf{9 6 \%}$ \\
\hline Serra do Navio & 3.765 & 4.850 & 1.085 & \\
\hline Incremento Líquido/ Relativo & & & \\
\hline
\end{tabular}

Embora Tartarugalzinho e Pedra Branca do Amapari em 2016 não estejam entre os municípios com maior população, estes foram os que apresentaram os maiores percentuais de crescimento populacional, com 226 e $225 \%$ respectivamente. No entanto, o maior incremento populacional em números líquidos, desconsiderando a capital Macapá e sua vizinha Santana, ocorreu nos municípios de Laranjal do Jari, Oiapoque, Porto Grande e Tartarugalzinho (AMAPÁ, 2014).

Destaca-se que todos os municípios apresentaram um alto crescimento populacional relativo se comparado a média brasileira que foi de $17 \%$. Para efeitos de comparação, na tabela 4 apresenta-se em ordem decrescente o desmatamento nos municípios amapaenses verificado pelo INPE através do Projeto PRODES no período de 2000 a 2014.

Tabela 4: Área desmatada nos Municípios amapaenses no período de 2000 a 2014, segundo dados do PRODES.

\begin{tabular}{|c|c|c|}
\hline & Município & \\
& & Área desmatada $\mathbf{2 0 0 0 - 2 0 1 4} \mathbf{( k m}^{\mathbf{2}} \mathbf{~}$ \\
\hline 1 & Tartarugalzinho & 185,12 \\
\hline 2 & Calçoene & 174,36 \\
\hline 3 & Macapá & 161,67 \\
\hline 4 & Porto Grande & 150,62 \\
\hline 5 & Pedra B. do Amapari & 115,74 \\
\hline 6 & Oiapoque & 104,84 \\
\hline 7 & Amapá & 71,84 \\
\hline 8 & Laranjal do Jari & 71,05 \\
\hline 9 & Mazagão & 60,8 \\
\hline
\end{tabular}




\begin{tabular}{|c|c|c|}
\hline 10 & Cutias & 53,59 \\
\hline 11 & Itaúbal & 46,56 \\
\hline 12 & Ferreira Gomes & 43,55 \\
\hline 13 & Pracuúba & 40,95 \\
\hline 14 & Vitória do Jari & 29,33 \\
\hline 15 & Serra do Navio & 29,03 \\
\hline 16 & Santana & 16,25 \\
\hline \multicolumn{2}{|c|}{ Total $\left(\mathbf{k m}^{2}\right)$} & 1355,3 \\
\hline
\end{tabular}

Fonte: INPE (2016b).

Com base na tabela 4, observa-se que os municípios que obtiveram maiores índices de crescimento populacional, ou em termos líquidos ou em termos relativos, foram os municípios que mais desmataram. Com a exceção do município de Calçoene, que apesar de não figurar entre os municípios com maior crescimento demográfico apresentou a segunda maior área desmatada no período e do município de Santana, que apresentou forte crescimento demográfico em termos líquidos e baixos índices de área desmatada.

Apesar do alto crescimento populacional em termos líquidos, o município de Laranjal de Jari não está entre os municípios com maior desmatamento, isto pode estar relacionado ao fluxo migratório ligado à oferta de empregos, principalmente na área de silvicultura, na indústria de celulose e de mineração existentes na região. Além disso, grande parte das terras próximas ao município de Laranjal do Jari é de propriedade do Projeto Jari, que realiza fiscalização constante na área para evitar invasões, no entanto elas ainda acontecem e historicamente tem gerado conflitos.

Assim como o Projeto Jari, outros empreendimentos de grande porte tiveram papel fundamental no crescimento demográfico e nas mudanças de uso do solo no estado do Amapá. Estes grandes empreendimentos geram inicialmente um grande fluxo migratório aumentando a população urbana e posteriormente, uma pressão por novas áreas para agricultura e pecuária.

Este processo também ocorreu na região central do Estado, tendo seu início na década de 1950, com o empreendimento de extração mineral do manganês do Grupo ICOMI no município de Serra do Navio desativado na década de 2000, gerando grande desemprego na região (DRUMMOND et al., 2007). Também na década de 2000, destaca-se a implantação de um grande empreendimento de extração do minério de ferro em Pedra Branca do Amapari, que teve grande crescimento demográfico no período (2000-2014).

Segundo AMAPÁ (2014a), a evolução demográfica que ocorre atualmente no Amapá, é associada ao padrão "subfronteiras de investimentos concentrados" que ocorre na Amazônia em geral, a qual consiste na entrada inicial de capital público e/ou privado, a qual é atrativa para a imigração. Este comportamento demográfico foi definido da seguinte forma: População e densidade populacional iniciais muito baixas; Taxas subitamente altas de crescimento ligadas a vultuosos investimentos públicos e/ou privados - taxas estas que, depois de algum tempo, declinam gradualmente; Grandes fluxos de migrantes de outros estados e até de outras regiões; e Crescimento mais rápido de populações urbanas, antes da ocupação plena das áreas rurais.

Em relação a esta evolução demográfica, o Poder Público (Governo Federal e Estadual) teve grande papel no acentuado crescimento demográfico ocorrido. Segundo Cruz et al. (1999), Amapá e Roraima foram os estados que mais se beneficiaram com a elevação para a categoria de Estado na Constituição de 1988, 
uma vez que estes estados foram os que mais receberam recursos federais em termos per capita, principalmente na década de 1990. Ainda de acordo com estes autores, estes dois estados, devido ao caráter geográfico isolado, baixa densidade demográfica e a ampla área de fronteira internacional exigiram maiores esforços de integração com o resto do país, inclusive com políticas de migração para ocupação do território por parte do governo federal.

Neste sentido, os projetos de assentamentos da reforma agrária promovidos pelo Instituto Nacional de Colonização e Reforma Agrária (INCRA), também são grandes responsáveis pelo crescimento populacional acima da média nacional ocorrido no Amapá. Entre 1987 e 2006 foram criados 29 assentamentos, que beneficiaram 7.421 famílias de trabalhadores rurais tanto do Amapá, quanto do Pará, Maranhão, Piauí, Ceará e Goiás. Importa destacar que até 2002 a maioria dos assentamentos surgiu espontaneamente a partir da invasão de terras públicas por migrantes, especialmente de nordestinos, os quais foram responsáveis pela ocupação de quase 1 milhão de hectares, equivalentes a aproximadamente a 7\% da área total do Estado, cabendo ao INCRA apenas o papel de regularizador desta situação (AMAPÁ, 2010).

De acordo com o AMAPÁ (2010), 50\% dos assentados retornaram para as cidades pois, além da falta de infraestrutura, de organização e garantia da produção, a falta de vocação dos assentados para a agricultura foram responsáveis pela alta taxa de evasão nos assentamentos. Estima-se que aproximadamente $80 \%$ das famílias que abandonaram os assentamentos procuraram Macapá para fixar residência, contribuindo para o vertiginoso aumento populacional da capital. As altas taxas de migração foram constatadas em 10 dos 16 municípios abrangidos pela Floresta Estadual do Amapá (FLOTA) (AMAPÁ, 2014a). Neste sentido, na figura 3 demonstra-se como a migração tem contribuído para o aumento populacional nos municípios abrangidos pela Unidade de Conservação (UC).

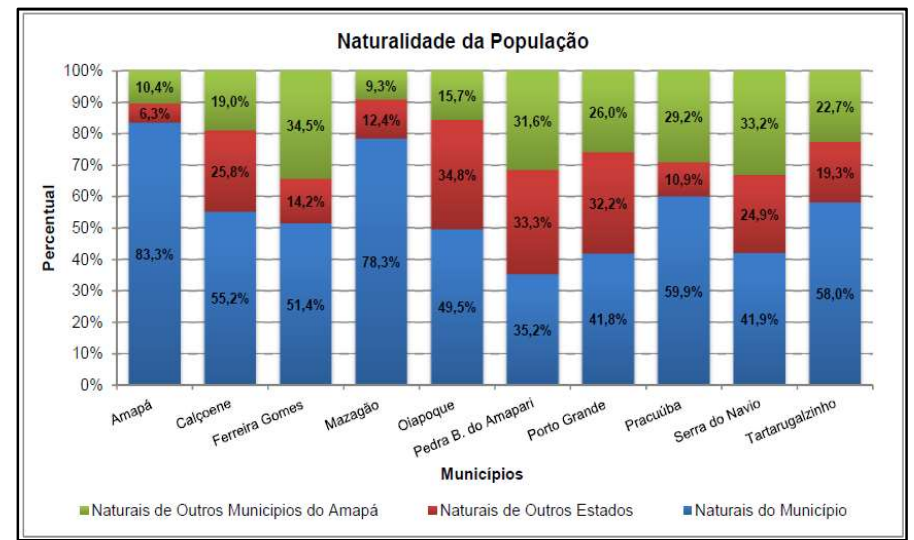

Figura 3: Naturalidade dos moradores residentes nos 10 municípios abrangidos pela Flota Amapá segundo o Censo Demográfico de 2010. Fonte: AMAPÁ (2014aa).

Historicamente, o Estado do Amapá passou por momentos de intensa migração, em decorrência do extrativismo, do comércio das 'drogas do sertão', posteriormente decorrente da exploração mineraria, pela criação do Estado do Amapá, criação das Áreas de Livre Comércio e atualmente o avanço da fronteira agrícola é o principal fator de migração atualmente (AMAPÁ, 2014a).

Ainda que a maior parte do crescimento populacional esteja concentrada em áreas urbanas, diminuindo assim a pressão nas áreas rurais, o crescimento populacional gera impactos diretos na floresta, 
como por exemplo elevando a demanda por produtos florestais, principalmente a madeira, que é utilizada na construção civil em geral. Na tabela 5 visualiza-se que 43,7\%, cerca de 68.145 domicílios do Amapá, são construídos com madeira ou outro material de origem florestal.

Tabela 4: Número de domicílios e tipo de material das paredes externas com base nos dados do IBGE (2014).

\begin{tabular}{|c|c|c|}
\hline Domicílios particulares permanentes por tipo de material das paredes externas & $\mathbf{N}^{\circ}$ de domicílios & (\%) \\
\hline Alvenaria com revestimento & 70.084 & 45 \\
\hline Alvenaria sem revestimento & 17.454 & 11 \\
\hline Madeira aparelhada & 61.344 & 39 \\
\hline Taipa revestida & 243 & 0,2 \\
\hline Taipa não revestida & 619 & 0,4 \\
\hline Madeira aproveitada & 5.773 & 4 \\
\hline Palha & 166 & 0,1 \\
\hline Outro material & 457 & 0,3 \\
\hline Total de domicílios de algum tipo de Material Vegetal & 68.145 & 43,6 \\
\hline Total de domicílios & $\mathbf{1 5 6 . 1 4 0}$ & $\mathbf{1 0 0}$ \\
\hline
\end{tabular}

Tabela 5: Quantidade produzida na extração vegetal, por tipo de produto extrativo com base no IBGE (2016d).

\begin{tabular}{|c|c|c|c|}
\hline Ano & Carvão vegetal (Toneladas) & Lenha (Metros cúbicos) & $\begin{array}{c}\text { Madeira em tora (Metros } \\
\text { cúbicos) }\end{array}$ \\
\hline 2000 & 399 & 66390 & 84410 \\
\hline 2001 & 372 & 57474 & 71367 \\
\hline 2002 & 387 & 63856 & 78493 \\
\hline 2003 & 369 & 65738 & 76574 \\
\hline 2004 & 436 & 83721 & 94777 \\
\hline 2005 & 451 & 93096 & 106114 \\
\hline 2006 & 463 & 118004 & 149930 \\
\hline 2007 & 435 & 124565 & 154407 \\
\hline 2008 & 477 & 163191 & 255106 \\
\hline 2009 & 515 & 174222 & 266925 \\
\hline 2010 & 594 & 191020 & 310506 \\
\hline 2011 & 729 & 267048 & 427809 \\
\hline 2012 & 829 & 320862 & 531491 \\
\hline 2013 & 961 & 393580 & 630674 \\
\hline
\end{tabular}

Nota-se que ocorreu um aumento significativo da produção de madeira em tora, de aproximadamente $608 \%$, entre 2000 e 2014. No entanto, cabe cautela na utilização destes dados, uma vez que o monitoramento da extração vegetal sofreu diversas alterações, visando o seu aprimoramento desde a década passada (2000).

Além do aumento na demanda por produtos florestais, o crescimento populacional aumenta a demanda por alimentos, viabilizando as atividades agropecuárias que na Amazônia são as maiores responsáveis pelo desmatamento de novas áreas, fazendo parte de um ciclo geralmente iniciado com a exploração madeireira. Prates e Bacha (2011) observaram que Mato Grosso, Maranhão, Pará e Rondônia em que o Produto Interno Bruto (PIB) Agropecuário têm maior importância também são os Estados que mais desmataram. Portanto, o crescimento populacional gera pressão e impacto indireto no aumento de áreas desmatadas.

A atividade pecuária tem se expandido na Amazônia para atender o mercado interno e externo. No entanto, a partir da análise dos dados sobre a exportação do Estado do Amapá, observa-se que a participação de produtos de origem animal nas exportações é muito baixa, especificamente $0,5 \%$ para o ano de 2012, 
levando a inferir que esta atividade visa atender a demanda interna² (AMAPÁ, 2014b). Na Tabela 6 são expostos os dados da série histórica populacional, do desmatamento, do rebanho bovino, e da agricultura no período de 2000 a 2014 no Amapá. Com base nos dados da tabela 6, calculou-se a correlação (r) entre os fatores, os quais foram dispostos na tabela 7.

Tabela 6: Série histórica da área desmatada dos fatores de indução do desmatamento.

\begin{tabular}{|c|c|c|c|c|}
\hline Ano & População total & Área Desmatada (ha) & Rebanho (Cabeça) & Área plantada (ha) \\
\hline 2000 & 499.329 & 164.230 & 82.822 & 9.684 \\
\hline 2001 & 519.202 & 189.870 & 87.197 & 13.667 \\
\hline 2002 & 538.836 & 196.680 & 83.901 & 13.962 \\
\hline 2003 & 558.398 & 239.100 & 81.674 & 13.475 \\
\hline 2004 & 577.786 & 249.270 & 82.243 & 14.424 \\
\hline 2005 & 596.914 & 255.230 & 96.527 & 16.433 \\
\hline 2006 & 615.692 & 260.090 & 109.081 & 18.170 \\
\hline 2007 & 634.068 & 269.350 & 103.170 & 21.418 \\
\hline 2008 & 651.977 & 279.230 & 95.803 & 23.985 \\
\hline 2009 & 669.360 & 283.950 & 104.977 & 25.512 \\
\hline 2010 & 686.189 & 291.020 & 114.773 & 25.362 \\
\hline 2011 & 702.638 & 292.650 & 127.499 & 24.743 \\
\hline 2012 & 718.906 & 294.530 & 142.825 & 28.120 \\
\hline 2013 & 734.996 & 296.892 & 154.967 & 43.172 \\
\hline 2014 & 750.912 & 299.760 & 162.411 & \\
\hline
\end{tabular}

Tabela 8: Correlação dos Fatores de indução ao desmatamento no Estado do Amapá.

\begin{tabular}{|l|c|}
\hline Fatores de Indução & Correlação \\
\hline População e Área desmatada & 0,95 \\
\hline População e Rebanho & 0,90 \\
\hline População e Agricultura & 0,90 \\
\hline Área desmatada e Rebanho & 0,74 \\
\hline Área desmatada e Agricultura & 0,77 \\
\hline
\end{tabular}

Destaca-se que todos os fatores analisados obtiveram forte correlação positiva entre si, no entanto a maior correlação apresentada foi entre crescimento demográfico e área desmatada $(r=0,95)$. Ao analisar a correlação dos fatores de indução diretos e indiretos, é interessante realizar a importante ressalva, que apesar alta correlação encontrada entre a área desmatada e crescimento populacional, deve-se levar em consideração que o projeto PRODES tem dificuldades em analisar as áreas desmatadas no Estado do Amapá.

Isso devido a dois fatores fundamentais: a alta incidência de nuvens nas imagens obtidas pelo sensor LANDSAT 5, que ocorre pelo fato do Estado estar geograficamente situado na Zona de Convergência Intertropical; e pelo perfil de pequenos desmatamentos no Estado, ligado a agricultura de Corte e Queima, os quais não são possíveis de serem identificados por meio da metodologia utilizada pelo projeto, que identifica somente desmatamentos com área maior que 6,25 hectares.

Apesar de estes dois fatores influenciarem diretamente nas taxas anuais emitidas pelo PRODES, sendo provável que um desmatamento não identificado em um ano devido a ocorrência de nuvens, possa ser identificado nos anos posteriores, a alta correlação apresentada chama a atenção. Importa destacar também, a alta correlação entre população e as atividades agropecuárias, sendo esta mais forte que a correlação entre as atividades agropecuárias e área desmatada. Demonstrando que outros fatores também podem estar influenciando no desmatamento, neste sentido Guadalupe (2018), ao estudar as mudanças de

\footnotetext{
${ }^{2}$ Cabe ressalva para o município do Oiapoque em que existe um comércio informal de carne bovina com a Guiana Francesa.
} 
uso do solo no norte do Estado (municípios de Oiapoque e Calçoene), verificou uma baixa relação de cabeça de gado por hectare, levando-o a inferir que a pecuária nestes municípios tinha fins especulativos.

Cabe lembrar, que o município de Calçoene, foi o único que apresentou altas taxas de desmatamento e um baixo crescimento populacional. Considerando a alta correlação encontrada entre crescimento demográfico e área desmatada, através do método estatístico da Regressão Linear foi realizada a projeção do desmatamento para o Estado do Amapá até o ano de 2030 utilizando dados do IBGE (2016g) (figura 4; tabela 9).

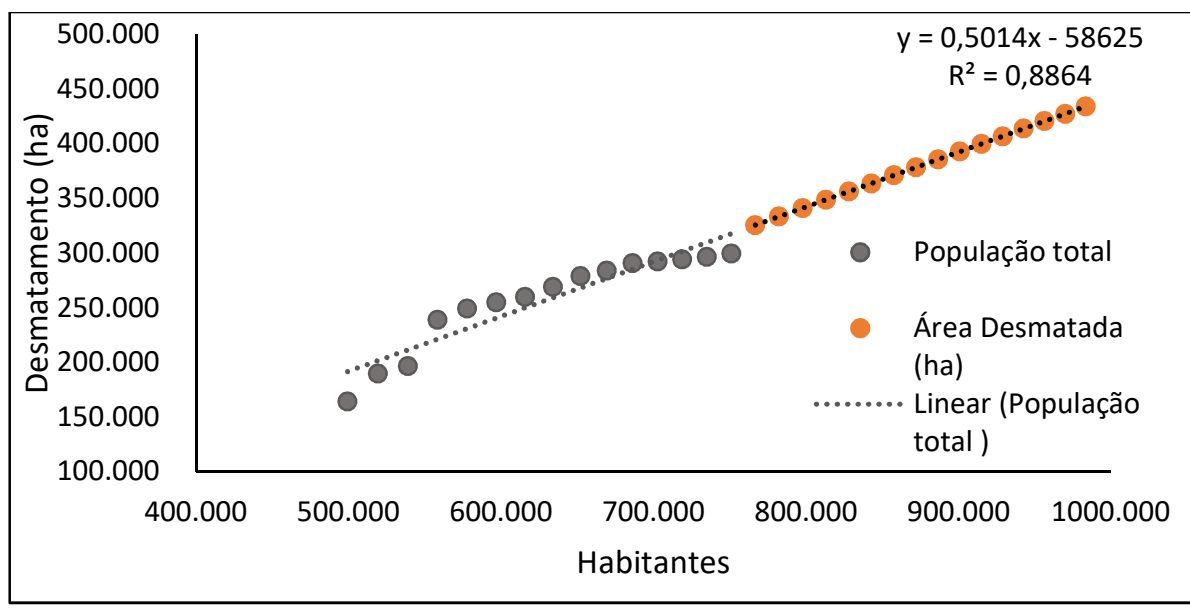

Figura 4: Projeção do desmatamento baseado no crescimento populacional.

Tabela 9: Projeção da área desmatada para o ano de 2030 no Estado do Amapá.

\begin{tabular}{|c|c|c|}
\hline Ano & População total & Área Desmatada (ha.) \\
\hline 2015 & 766.679 & 325.788 \\
\hline 2016 & 782.295 & 333.618 \\
\hline 2017 & 797.722 & 341.353 \\
\hline 2018 & 812.961 & 348.994 \\
\hline 2019 & 828.028 & 356.548 \\
\hline 2020 & 842.914 & 364.012 \\
\hline 2021 & 857.634 & 371.393 \\
\hline 2022 & 872.187 & 378.690 \\
\hline 2023 & 886.586 & 385.909 \\
\hline 2024 & 900.828 & 393.050 \\
\hline 2025 & 914.915 & 400.113 \\
\hline 2026 & 928.861 & 407.106 \\
\hline 2027 & 942.678 & 414.034 \\
\hline 2028 & 956.359 & 420.893 \\
\hline 2029 & 969.906 & 427.686 \\
\hline 2030 & 983.304 & 434.404 \\
\hline
\end{tabular}

De acordo com os resultados obtidos através da projeção de crescimento demográfico, o Estado do Amapá apresenta tendência de desmatar mais 134.644 ha até 2030 , que equivalem a cerca de $45 \%$ do porcentual desmatado até 2014. Destaca-se que o Brasil assumiu como meta na COP-21 de Paris, o compromisso de zerar o Desmatamento llegal na Amazônia até o ano de 2030 (OC, 2015).

Adicionalmente, o Estado do Amapá é considerado a última fronteira agrícola do país, evidenciando a expansão agrícola da região do Cerrado Amapaense, a Embrapa Amapá (2013) realizou levantamento das safras agrícolas (2012-2013) que indicou a evolução da área plantada, de aproximadamente 2.500 para quase 10.000 hectares, entre os anos de 2012 e 2013. O Estado conta com cerca de 1 milhão de hectares de cerrado, dos quais cerca de 400.000 são aptos para agricultura. A Associação de Produtores de Soja do Amapá 
(APROSOJA) criada em 2015 possui cerca de 200 produtores com a estimativa do cultivo de 15.000 hectares de soja, além de outras culturas como arroz, milho e feijão caupi.

Portanto, constata-se uma mudança de cenário para a economia agrícola amapaense, que até poucos anos atrás visava abastecer somente o mercado local dependendo de subsídios do governo, devido aos elevados custos de produção e de logística em função do isolamento geográfico e baixa tecnologia. Atualmente a localização geográfica do Estado se transformou em vantagem competitiva, uma vez que agora faz parte da rota de escoamento de grãos do Estado do Mato Grosso e navios que tem como destino os portos de Santarém (PA) e Itacoatiara (AM) passaram a ter como rota o porto de Santana-AP, onde já foram embarcadas as primeiras 25 mil toneladas de soja 100\% produzidas em solo amapaense (FREITAS JUNIOR, 2013; SANTOS, 2016).

\section{CONCLUSÃO}

O caráter geográfico isolado do Amapá do restante do Brasil somado à uma população pequena e concentrada, contribuiu para o elevado grau de preservação da cobertura vegetal nativa. No entanto, observou-se que nas duas últimas décadas esse cenário está mudando em decorrência de vários fatores, sendo um deles a alta taxa de natalidade e de migração no Estado. Evidencia-se que o Amapá registra as maiores médias anuais de crescimento populacional, quando comparado a região Norte e o restante do país.

O alto índice de crescimento populacional no Estado decorre principalmente de incentivos governamentais, como alto aporte de dinheiro através dos repasses federais, políticas de ocupação do espaço amapaense através de grandes obras de infraestrutura e políticas de reforma agrária. O setor privado contribui para os altos índices de crescimento populacional por meio da implantação de grandes empreendimentos no Estado.

O crescimento populacional apresentou uma relação direta com o aumento do desmatamento por ocasionar a elevação na demanda por alimentos e produtos florestais, os quais acabam impactando diretamente na conversão de áreas florestadas em pastagens e lavouras. A partir das estimativas realizadas no estudo a tendência é aumento do desmatamento devido ao contínuo crescimento populacional e possíveis mudanças no perfil da agropecuária, que até o presente visava principalmente o abastecimento do mercado interno, mas com a inclusão do Estado na rota de exportação de commoditties, têm atraído a migração de novos atores, capitalizados e com expertise na produção de grãos.

\section{REFERÊNCIAS}

AEM. Avaliação Ecossistêmica do Milênio. Ecossistemas e o Bem-estar Humano: Estrutura para uma avaliação.

Washington: Island Press, 2003.

AMAPÁ. Anuário Estatístico do Estado do Amapá 2011-

2012. Macapá: 2014.

AMAPÁ. Plano de Manejo da Floresta Estadual do Amapá. Macapá: 2013.
BUTLER, R.. Calculating Deforestation Figures for the Amazon. Mongabay: The Amazon Rain Forest, 2017.

COUTINHO, A.; ALMEIDA, C.; VENTURIERI, A.; ESQUERDO, J.; SILVA, M.. Uso e cobertura da terra nas áreas desflorestadas da Amazônia Legal. Brasília: EMBRAPA, 2013.

CRUZ, B.; OLIVEIRA, C.. Federalismo, Repasses Federais e Crescimento Econômico: um Estudo sobre Amapá e Roraima. Brasília: IPEA, 1999. 
DRUMMOND, J.; PEREIRA, M.. O Amapá em tempos do Manganês: Um estudo sobre o desenvolvimento de um estado amazônico. Rio de Janeiro: Garamond, 2007.

FREITAS JUNIOR, G.. Megainvestimento abre nova rota para soja. São Paulo: Jornal Valor, 2013.

GEIST, H.; LAMBIN, E.. Proximate causes and underlying driving forces of tropical deforestation. BioScience, v.52, n.2, p.143-150, 2002. DOI: https://doi.org/10.1641/00063568(2002)052[0143:PCAUDF] 2.0.CO;2

AMAPÁ. Plano de Prevenção e Combate ao DesmatamentoPPCDAP: 2010-2014. Macapá: WWF, 2010.

GUADALUPE, V.; SOTTA, E. D.; SANTOS, V. F.; AGUIAR, L. J. G.; OLIVEIRA, C. P.; SIQUEIRA, J. V. N. REDD+ implementation in a high forest low deforestation area: Constraints on monitoring forest carbon emissions. Land Use Policy, v.76, p.414-421, 2018. DOI:

https://doi.org/10.1016/i.landusepol.2018.02.015

IBGE. Instituto Brasileiro de Geografia e Estatística. Dados geográficos do estado do Amapá. Rio de Janeiro: IBGE, 2016a.

IBGE. Instituto Brasileiro de Geografia e Estatística. Estimativas de População. Rio de Janeiro: IBGE, 2016c.

IBGE. Instituto Brasileiro de Geografia e Estatística. Pesquisa Nacional por Amostra de Domicílios Contínua. Rio de Janeiro: IBGE, 2014.

IBGE. Instituto Brasileiro de Geografia e Estatística. Produção Agrícola Municipal. Rio de Janeiro: IBGE, $2016 f$.

IBGE. Instituto Brasileiro de Geografia e Estatística. Produção da Extração Vegetal e da Silvicultura. Rio de Janeiro: IBGE, 2016d.
IBGE. Instituto Brasileiro de Geografia e Estatística.

Produção Pecuária Municipal. Rio de Janeiro: IBGE, $2016 \mathrm{e}$.

IBGE. Instituto Brasileiro de Geografia e Estatística. Projeção da população do Brasil e das Unidades da Federação. Rio de Janeiro: IBGE, 2016g.

IBGE. Instituto Brasileiro de Geografia e Estatística. Tendências Demográficas. Rio de Janeiro: IBGE, 2016b.

INPE. Instituto Nacional de Pesquisas Espaciais.

Desmatamento nos Municípios: Monitoramento da Floresta Amazônica Brasileira por Satélite - PRODES. Brasília: INPE, 2015b.

INPE. Instituto Nacional de Pesquisas Espaciais. Divulgação do PRODES. Brasília: INPE, 2015a.

OC. Observatório do Clima. Brasil registra sua meta para o acordo do clima de Paris. Brasília: OC, 2015.

PRATES, R.; BACHA, C.. Os processos de desenvolvimento e desmatamento da Amazônia. Economia e Sociedade, v.20, p.3-43, 2011. DOI:

http://doi.org/10.1590/S010406182011000300006

QUÉRÉ, C.; MICHAEL, R.; RAUPACH, M.; CANADELL, J.; MARLAND, G.. Trends in the sources and sinks of carbon dioxide. Nature Geoscience, v.2, p.831-836, 2009. DOI: http://doi.org/10.1038/ngeo689

RABELO, B.. Macrodiagnóstico do Estado do Amapá: primeira aproximação do ZEE. 3 ed. Macapá: IEPA, 2008. SANTOS, A.. Amapá dá primeiro passo para exportação de soja. Macapá: 2016.

VIANA, V.; VIANA, C.; EULER, A.; GRIEG-GRAN, M.; BASS, S.. Economia Verde no Estado do Amapá, Brasil: Avanços e perspectivas. London: IIED, 2014.

A CBPC - Companhia Brasileira de Produção Científica (CNPJ: 11.221.422/0001-03) detém os direitos materiais desta publicação. Os direitos referem-se à publicação do trabalho em qualquer parte do mundo, incluindo os direitos às renovações, expansões e disseminações da contribuição, bem como outros direitos subsidiários. Todos os trabalhos publicados eletronicamente poderão posteriormente ser publicados em coletâneas impressas sob coordenação da Sustenere Publishing, da Companhia Brasileira de Produção Científica e seus parceiros autorizados. Os (as) autores (as) preservam os direitos autorais, mas não têm permissão para a publicação da contribuição em outro meio, impresso ou digital, em português ou em tradução. 